\title{
Predictive value of geriatric-quickSOFA in hospitalized older people with sepsis
}

\author{
Francesca Remelli ${ }^{1,2}$, Federico Castellucci ${ }^{1}$, Aurora Vitali ${ }^{1,2}$, Irene Mattioli ${ }^{1,2}$, Amedeo Zurlo $^{1,2}$, Savino Spadaro ${ }^{3}$ and
} Stefano Volpato ${ }^{1,4^{*}}$

\begin{abstract}
Background: QuickSOFA, a prognostic score proposed for patients with infection, has shown a poor predictive value in the geriatric population, probably because of the inappropriateness of the Glasgow Coma Scale (GCS) in assessing acute alteration of mental status in older patients. Indeed, the GCS might result chronically low in older patient with pre-existing cognitive disorders. The aim of this study was to develop an alternative quickSOFA (geriatric-quickSOFA), using the presence of delirium, assessed according to DSM-5 criteria, instead of GCS assessment, to predict mortality in hospitalized older patients with sepsis.
\end{abstract}

Methods: Retrospective observational study in Acute Geriatrics Unit of St. Anna Hospital of Ferrara (Italy). The study enrolled 165 patients hospitalized between 2017 and 2018 with diagnosis of sepsis or septic shock. Demographic, clinical data and 30-day survival were collected for each patient. Based on arterial blood pressure, respiratory rate, and the presence of delirium, geriatric-quickSOFA was calculated at admission. Primary outcome was 30-day mortality.

Results: One hundred sixty-five patients were enrolled with a median age of 88 years; $60.6 \%$ were men. High quickSOFA score was not significantly correlated neither with in-hospital nor 30-day mortality. High geriatric-qSOFA score was significantly related to both in-hospital (13.3\%vs $51.5 \%, p=0.0003)$ and 30 -day mortality (30.0\%vs $84.3 \%$, $p<0.00001)$.

Conclusion: Geriatric-quickSOFA is significantly associate with short-term mortality risk in older patients with sepsis. Geriatric quickSOFA seems to represent a more suitable and useful predictive tool than the traditional quickSOFA in the geriatric population.

Keywords: Elderly, Sepsis, Delirium, QuickSOFA, Geriatric-quickSOFA

\section{Background}

Sepsis is a major public health problem in older people being one of the most common cause of hospitalization, disability and death [1-4]. A recent retrospective population-based study has shown that death due to sepsis is increasing over time, explaining more the one third of all deaths among patients aged 85 and older [5]. Early identification of high risk

\footnotetext{
* Correspondence: vlt@unife.it

'Department of Medical Sciences, University of Ferrara, Ferrara, Italy

${ }^{4}$ Orthogeriatrics Unit, Azienda Ospedaliero-Universitaria di Ferrara, Via Aldo Moro, 8, 44124 Ferrara, Italy

Full list of author information is available at the end of the article
}

patients is essential for better prognosis and survival, but in older patients both the diagnosis and prognosis of sepsis are challenging, because of the high variability of clinical presentations with atypical symptoms including, confusional status and delirium [6-10].

For an early recognition of high risk patients with sepsis, a simplified version of the original SOFA, quickSOFA (qSOFA), score has been proposed [11, 12] based on the presence of arterial hypotension, tachypnea and altered mental status defined as a Glasgow Coma Scale $(\mathrm{GCS}) \leq 14$.

C C The Author(s). 2021 Open Access This article is licensed under a Creative Commons Attribution 4.0 International License, which permits use, sharing, adaptation, distribution and reproduction in any medium or format, as long as you give appropriate credit to the original author(s) and the source, provide a link to the Creative Commons licence, and indicate if changes were made. The images or other third party material in this article are included in the article's Creative Commons licence, unless indicated otherwise in a credit line to the material. If material is not included in the article's Creative Commons licence and your intended use is not permitted by statutory regulation or exceeds the permitted use, you will need to obtain permission directly from the copyright holder. To view a copy of this licence, visit http://creativecommons.org/licenses/by/4.0/. The Creative Commons Public Domain Dedication waiver (http://creativecommons.org/publicdomain/zero/1.0/) applies to the data made available in this article, unless otherwise stated in a credit line to the data. 
Few studies have investigated the predictive value of the qSOFA in older patients, mainly in Intensive Care Unit (ICU) wards, [13-19] providing discordant results and suggesting only a weak correlation between qSOFA score and mortality risk. One explanation for the poor predictive value might be the inability of the GCS in assessing mental status changes and fluctuations of acutely ill patients when affected by pre-existing cognitive decline and/or delirium. For example, a patient with severe cognitive impairment might be categorized as having a low GCS because unable to answer simple verbal questions, regardless of the acute effect of sepsis on mental status.

The aim of our study was, therefore, to develop a modified version of the qSOFA to be used in older patient. We hypothesized that a score including the presence of delirium instead of abnormal GCS might have better prognostic value because more specific in assessing the acute mental impairment often present in older patients with sepsis.

\section{Methods}

\section{Participant recruitment}

This is a retrospective study carried out in the Acute Geriatrics Unit of the University Hospital of Ferrara (Italy) between January 2017 and December 2018. The study enrolled patients discharged with diagnosis of sepsis or septic shock. The data for patient selection were obtained from hospital database system. Diagnosis of sepsis was verified according to sepsis-3 criteria [1]. From the initial sample of 243 patients, 183 clinical records were available via hospital database.

Demographic characteristics and pre-admission functional status were collected from clinical interview. Cognitive status was assessed at admission using the Short Portable Mental Status Questionnaire (SPMSQ) and GCS; the diagnosis of delirium was performed according to Diagnostic and Statistical Manual of Mental Disorders 5th (DSM-5th) Edition criteria [20]. Among chronic diseases, congestive heart failure, diabetes, cancer and cognitive decline were collected; comorbidity was assessed using the Charlson Comorbidity Index (CCI) [21]. All drugs currently taken by the patients on admission were recorded; number of drugs taken was also calculated.

Information regarding clinical chemistry tests were collected; white blood cells, hemoglobin, platelet count, creatinine, bilirubin, albumin, $\mathrm{pH}, \mathrm{C}$-reactive protein, procalcitonin were considered in the analyses.

\section{Prognostic scores and outcomes}

For each patient, arterial blood pressure, respiratory rate, mental status, evaluated through both GCS and presence of delirium were collected. Using this information, traditional quickSOFA and geriatric-quickSOFA were calculated. Geriatric-quickSOFA was based on the evaluation of three clinical parameters: arterial hypotension (Systolic Arterial Pressure $\leq 100 \mathrm{mmHg}$ ), tachypnea (Respiratory Rate $\geq 22 / \mathrm{min}$ ) and presence of delirium assessed by DSM-5th criteria. To each of these items the value " 1 " or "0" was assigned whether the sign was present or absent, respectively (score range $0-3$ ), Fig. 1. Because of missing data, qSOFA calculation was possible in 165 patients that represent the final study sample.

The primary outcome of the study was 30-day mortality, collected using hospital database; secondary outcome was in-hospital mortality.

\section{Statistical analysis}

The main demographic and clinical features of patients enrolled were presented using mean and standard deviation for continuous variables; frequency and percentage for dichotomous ones. The characteristics of patients were compared according to in-hospital and 30-day mortality, using Student's t-test and Pearson's ChiSquare test for continuous and categorical variables, respectively.

The predictive performance of variables related to the primary outcome was assessed using multivariable logistic regression analysis and expressed through Odds Ratio with 95\% Confidence Interval (OR, 95\% CI). The better cut-off of geriatric-qSOFA score was evaluated through estimation of sensibility, specificity, prognostic OR, accuracy, and Youden index for both in-hospital and 30day mortality. $P$-value $<0.05$ were considered statistically significant.

Statistical analysis was performed using Software R.

\section{Results}

Median age of the 165 patients enrolled in the study was 88 years; $60.6 \%(n=100)$ were men. Most of patients enrolled had cognitive decline $(71.5 \%)$ with different stages of severity and impaired pre-admission functional status (median of Basic Activities of Daily Living and Instrumental Activities of Daily Living preserved were $1 / 6$ and $1 / 8$, respectively); $53.3 \%$ of the sample was bedridden before hospital admission; delirium occurred in over $60 \%$ of patients. All patients were affected by pre-existing multimorbidities with a median CCI of 4 out of 32 points. The most frequent primary sites of infection causing sepsis were urinary tract (38\%) and lungs (34\%). Thirty-seven percent of the sample $(n=61)$ had a qSOFA $\geq 2$. All-cause in-hospital mortality was $44.3 \%$ $(n=73)$ and 30 -day mortality was $75.2 \%(n=124)$.

The clinical and demographic characteristics of the population according to 30-day mortality are summarized in Table 1 . Clinical characteristics significantly correlated with 30-day mortality were bedridden status $(34.2 \%$ vs $58.9 \%, p=0.009)$, presence of tachypnea 


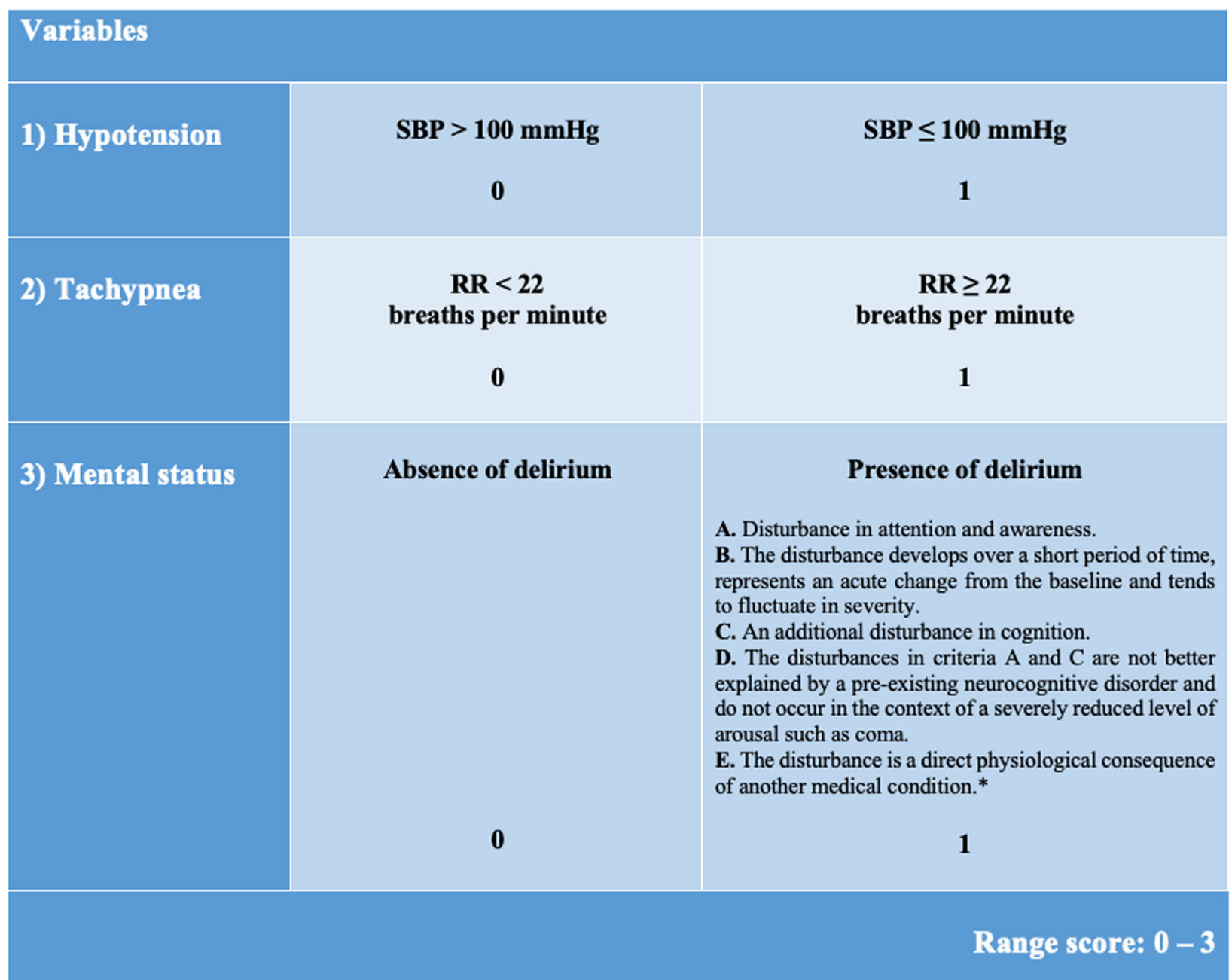

SBP: Systolic Blood Pressure; RR: Respiratory Rate. ${ }^{*} D S M-5$ th diagnostic criteria.

Fig. 1 Geriatric-quick SOFA

(17.1\% vs $35.5 \%, p=0.04)$, delirium $(41.5 \%$ vs $68.6 \%, p=$ 0.002 ), and low hemoglobin and albumin serum levels $(12.1 \mathrm{vs} 11.1 \mathrm{~g} / \mathrm{dl}, p=0.02$ and 2.8 vs $2.4 \mathrm{~g} / \mathrm{dl}, p=0.004$, respectively).

The traditional qSOFA was not significantly associated with 30-day mortality, whereas the new geriatricquickSOFA was strongly and significantly associated with both 30-day and in-hospital mortality (Fig. 2). Performance indicators of the two score are presented in Table 2. Based on sensibility, accuracy, OR and Youden index results for 30-day mortality, the best cut-off was defined at 1 .

Geriatric-qSOFA score $\geq 1$ was significatively related to in-hospital (13.3\% vs $51.5 \%, p=0.0003)$ and 30 -day mortality (30.0\% vs $84.3 \%, p<0.00001)$ (Fig. 2 ).

These results were confirmed in multivariable logistic regression analysis, adjusting for age, gender, bedridden status, functional status, and serum hemoglobin and albumin levels (Table 3). Patients with a high geriatricqSOFA at admission were 15 times more likely to die from sepsis at 30-day, as compared to patients with low geriatric-qSOFA. Furthermore each items of geriatric qSOFA was independently tested in single multivariable analyses adjusted for the same potential confounders: the geriatric qSOFA score had stronger predictive value and better perfomance than each single item in predicting 30-day mortality. In particular, delirium alone was also significantly correlated with the outcome (OR 5.16; 95\%CI 2.07-12.9), but the strength of the association was significantly lower as compared to the geriatricqSOFA. Moreover, geriatric qSOFA showed a higher sensitivity ( $92.6 \%$ versus $57.5 \%$ ), positive predictive value (84.3\% versus $41.5 \%)$, accurancy (81.7\% versus $68.0 \%)$ and Youden index (0.43 versus 0.29$)$ than delirium as single item.

Results were similar for in-hospital mortality. 
Table 1 Selected baseline characteristics of the population according with 30-day mortality

\begin{tabular}{|c|c|c|c|}
\hline Variables & $\begin{array}{l}\text { Survivors } \\
(n=41)\end{array}$ & $\begin{array}{l}\text { Deaths } \\
(n=124)\end{array}$ & $p$ \\
\hline Age, mean $\pm S D$ & $87.2 \pm 4.5$ & $87.6 \pm 5.7$ & 0.668 \\
\hline Male sex, $n(\%)$ & $29(70.7)$ & $71(57.3)$ & 0.196 \\
\hline Charlson Comorbidity Index, median [IQR] & $5[3,6]$ & $4[3,5]$ & 0.433 \\
\hline Cancer, $n(\%)$ & $6(14.6)$ & $23(18.6)$ & 0.723 \\
\hline Diabetes, n (\%) & $17(41.5)$ & $28(22.5)$ & 0.129 \\
\hline Chronic heart failure, $n(\%)$ & $15(36.6)$ & $48(38.7)$ & 0.926 \\
\hline Cognitive decline, $n(\%)$ & $26(63.4)$ & $91(73.4)$ & 0.273 \\
\hline Bedridden, $n$ (\%) & $14(34.2)$ & $73(58.9)$ & 0.009 \\
\hline SPMSQ, median [IQR] & $9[5,10]$ & $10[6,10]$ & 0.219 \\
\hline Number of drugs, median [IQR] & $6[5,9]$ & $7[5,9]$ & 0.897 \\
\hline BADL, median [IQR] & $1[0,1]$ & $0[0,1]$ & 0.614 \\
\hline IADL, median [IQR] & $0[0,1]$ & $0[0,0]$ & 0.791 \\
\hline Delirium, $n$ (\%) & $17(41.5)$ & $85(68.6)$ & 0.002 \\
\hline Prevalent, $n$ (\%) & $12(29.3)$ & $40(32.3)$ & 0.823 \\
\hline Incident, $n(\%)$ & $5(12.2)$ & $45(36.3)$ & 0.006 \\
\hline Hypotension, n (\%) & $11(26.9)$ & $44(35.5)$ & 0.390 \\
\hline Tachypnea, $n$ (\%) & $7(17.1)$ & $44(35.5)$ & 0.041 \\
\hline Altered mental status, $n$ (\%) & $19(46.4)$ & $66(53.2)$ & 0.528 \\
\hline White Blood Cells $(\times 10 \wedge 3 / \mu l)$, mean $\pm S D$ & $17.7 \pm 10.5$ & $15.4 \pm 9.2$ & 0.222 \\
\hline Hemoglobin $(g / d l)$, mean $\pm S D$ & $12.1 \pm 2.1$ & $11.1 \pm 2.5$ & 0.015 \\
\hline Platelets Count $(\times 10 \wedge 3 / \mu \mathrm{l})$, mean $\pm S D$ & $256.1 \pm 97.1$ & $242.0 \pm 114.6$ & 0.443 \\
\hline Creatinine $(\mathrm{mg} / \mathrm{dl})$, mean $\pm S D$ & $1.51 \pm 0.82$ & $1.80 \pm 1.22$ & 0.088 \\
\hline Bilirubin $\mathrm{mg} / \mathrm{dl})$, mean $\pm S D$ & $0.8 \pm 0.6$ & $0.9 \pm 0.8$ & 0.272 \\
\hline Albumin $(\mathrm{g} / \mathrm{dl})$, mean $\pm S D$ & $2.8 \pm 0.6$ & $2.4 \pm 0.8$ & 0.004 \\
\hline $\mathrm{pH}$, mean $\pm S D$ & $7.43 \pm 0.08$ & $7.43 \pm 0.09$ & 0.972 \\
\hline C Reactive Protein $(\mathrm{mg} / \mathrm{dl})$, mean $\pm S D$ & $14.7 \pm 8.6$ & $14.7 \pm 9.9$ & 0.980 \\
\hline Procalcitonin $(\mathrm{ng} / \mathrm{ml})$, mean $\pm S D$ & $25.0 \pm 37.0$ & $22.0 \pm 33.0$ & 0.673 \\
\hline
\end{tabular}

Note: SPMSQ Short Portable Mental Status Questionnaire (number of errors), BADL Basic Activities Of Daily Living, IADL Instrumental Activities of Daily Living; Hypotension = systolic blood pressure $<100 \mathrm{mmHg}$; tachypnea = Respiratory Rate $\geq 22 / \mathrm{min}$; altered mental status = Glasgow Coma Scale $\leq 14$

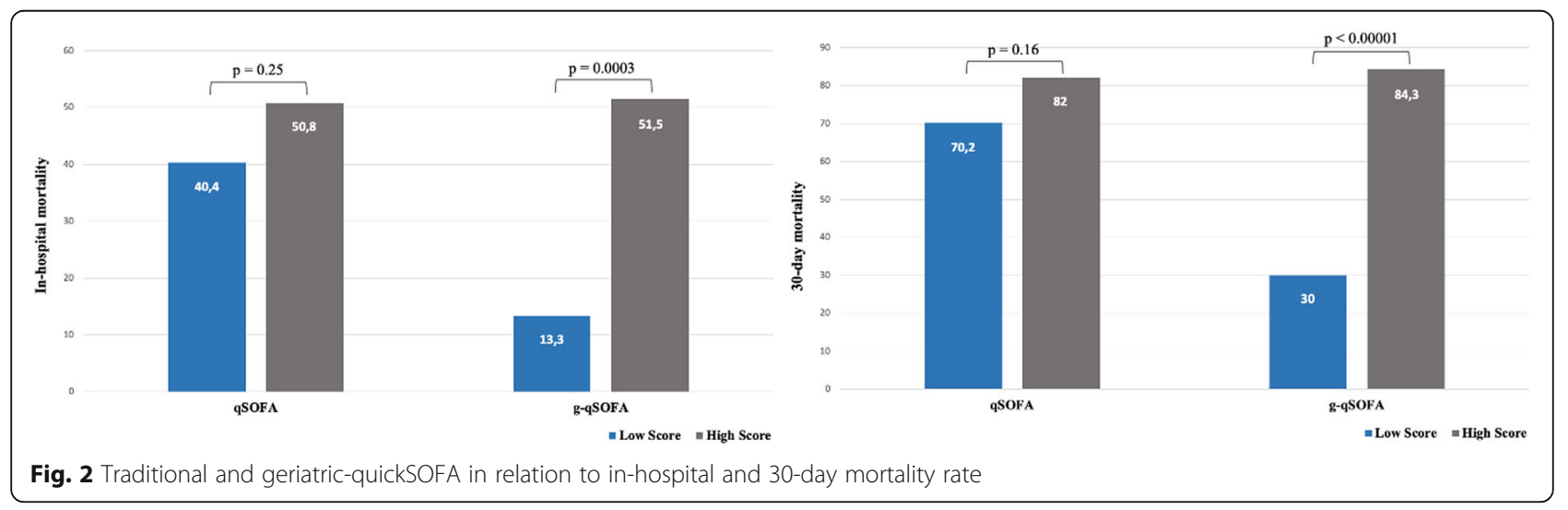


Table 2 Performance indicators of the traditional qSOFA and geriatric qSOFA

\begin{tabular}{lll}
\hline & qSOFA & Geriatric qSOFA \\
\hline Sensitivity & $73.2 \%$ & $92.6 \%$ \\
Specificity & $40.7 \%$ & $50.0 \%$ \\
OR & 1.87 & 12.5 \\
Accurancy & $48.8 \%$ & $81.7 \%$ \\
PPV & $29.1 \%$ & $84.3 \%$ \\
NPV & $81.9 \%$ & $70.0 \%$ \\
Youden index & 0.14 & 0.43 \\
\hline
\end{tabular}

Note: OR Odds Ratio, PPV Positive Predictive Value, NPV Negative Predictive Value

\section{Discussion}

In this study of older patients hospitalized with sepsis, original qSOFA was not associated with the risk of death, whereas a modified version, including presence of delirium as indicator of impaired mental status, was significantly associated with both in-hospital and 30-day mortality risk, supporting the hypothesis that qSOFA might not be an adequate prognostic tool in the geriatric population. In multivariable logistic regression analysis, adjusted for potential confounders, patients with a modified qSOFA score $\geq 1$ had an almost fifteen-fold risk of death compared to patients with a score of zero.

Our findings extend the results of previous studies providing new insight into the prognostic value of qSOFA in the geriatric population. The ability of qSOFA to predict the clinical course of older patients with sepsis has been already challenged in previous studies [13-17]. Most available studies were performed in ICU with discordant results. While in a study performed on 92 geriatric patients with sepsis admitted to ICU, a significant difference was found in 28-day mortality based on qSOFA value [13], others two recent studies have suggested a low discriminative performance of qSOFA on 30-day (AUC 0.640) [14] and in-hospital mortality (AUC
0.596) [15]. Also in studies conducted in non-ICU wards the prognostic value of qSOFA was not consistent. In a prospective study performed on a sample of 272 patients admitted to Geriatric Ward, qSOFA did not predict inhospital death and was related only with 3-month mortality [17]. Furthermore, in a recent study on a hospitalized population with median age of 75 years old, qSOFA was not an independent predictor of mortality [19]. On the contrary, in adults qSOFA shows a high sensitivity $(87.7 \%)$, negative predictive value $(96.6 \%)$ and accuracy (0.83) [18].

We have therefore developed an alternative qSOFA, respecting the principles under which traditional qSOFA was created (simple and based on clinical parameters without any laboratory tests), but more specifically tailored on older patient characteristics. In particular, we replaced the GCS item with presence of delirium as indicator of mental status impairment, as we hypothesised that delirium would be a more specific marker for the presence of underlying acute disease, as sepsis, and because it is correlated with a very high risk of death in older people [22-25]. Indeed, in addition to advanced age and frequent pre-existing cognitive impairment, presence of sepsis is a well-known trigger for delirium [25-27]. One additional explanation for the better performance of delirium as compared to GCS, initially created to evaluate the severity of impairment of consciousness in neuro-surgical patients with cerebral trauma [28], is that GCS might not be suitable for discriminating between acute and chronic cognitive disfunction including, but not limited to, pre-existing cognitive decline or behavioural and psychological symptoms of dementia. In other words, in acute ill geriatric patients with persistent and pre-existing cognitive dysfunction, GCS assessment might result in a false positive score, not being able to distinguish between acute and chronic dysfunction, with a possible consequent inappropriate hospitalization [29].

Table 3 Multivariate logistic regression analysis for the probability of 30-day mortality

\begin{tabular}{|c|c|c|c|c|c|}
\hline & $\begin{array}{l}\text { Model } 1 \\
\text { OR } \\
\text { (I.C. 95\%) }\end{array}$ & $\begin{array}{l}\text { Model } 2 \\
\text { OR } \\
\text { (I.C. 95\%) }\end{array}$ & $\begin{array}{l}\text { Model } 3 \\
\text { OR } \\
\text { (I.C. 95\%) }\end{array}$ & $\begin{array}{l}\text { Model } 4 \\
\text { OR } \\
\text { (I.C. 95\%) }\end{array}$ & $\begin{array}{l}\text { Model } 5 \\
\text { OR } \\
\text { (I.C. 95\%) }\end{array}$ \\
\hline g-qSOFA (cut-off $\geq 1$ ) & $11.96(4.79-29.84)$ & $12.64(4.89-32.70)$ & $13.23(4.95-34.77)$ & $11.45(4.27-30.72)$ & $15.63(3.88-62.99)$ \\
\hline Age & - & $0.98(4.48-2.54)$ & $0.99(0.37-2.61)$ & $0.98(0.36-2.62)$ & $0.99(0.25-3.99)$ \\
\hline Male sex & - & $1.73(0.67-4.48)$ & $1.71(0.65-4.53)$ & $1.70(0.63-4.56)$ & $2.74(0.68-11.05)$ \\
\hline $\mathrm{BADL}^{\mathrm{a}}$ & - & - & $1.03(0.39-2.74)$ & $1.05(0.39-2.83)$ & $1.25(0.31-5.10)$ \\
\hline $\mathrm{IADL}^{\mathrm{b}}$ & - & - & $1.01(0.38-2.69)$ & $0.99(0.37-2.65)$ & $0.75(0.19-3.02)$ \\
\hline Bedridden & - & - & - & $2.05(0.76-5.49)$ & $3.06(0.76-12.34)$ \\
\hline Hemoglobin & - & - & - & - & $0.89(0.22-3.61)$ \\
\hline Albumin & - & - & - & - & $0.19(0.05-0.76)$ \\
\hline
\end{tabular}

${ }^{a}$. BADL preserved ${ }^{b} \mathrm{n}$. IADL preserved. Model 1 (crude); Model 2 (+ age and gender); Model 3 (+ BADL and IADL); Model 4 (+ bedridden); Model 5 (+ hemoglobin and albumin) 
Based on statistical analysis, the better cut-off of geriatric-qSOFA score was defined at 1: a geriatricqSOFA $\geq 1$ at hospital admission was associated with an increased risk of in-hospital and 30-day mortality about 8 and 15 times higher as compared to patients with lower score. These estimates were independent of important potential confounders including demographic characteristics, functional status, hemoglobin and albumin levels, or well-known risk factors for mortality in older people. These findings further support the potential utility of geriatric-qSOFA as prognostic tool in geriatric patients with sepsis and multimorbidity.

In interpreting these findings some limitations should be considered. The retrospective observational design of the study might have introduced some degree of classification bias regarding qSOFA and delirium assessment. The small sample size reduced the statistical power of our analyses increasing the likelihood of type II error. Farther, more than $50 \%$ of the enrolled population was bedridden before hospital admission and this finding might have disproportionally increased mortality rate, independent of the severity of sepsis, reducing the external validity of our findings. Finally, we developed a modified version of the qSOFA but we were not able to validate it using either an internal or an external independent cohort.

\section{Conclusion}

In conclusion, our study suggests a new prognostic score, specifically tailored for the geriatric population, and designed to predict early mortality from sepsis in this group of patients.

These preliminary data need further investigations and prospective validation of its clinical use as prognostic score using independent cohorts of older population with sepsis.

\section{Abbreviations}

GCS: Glasgow Coma Scale; qSOFA: QuickSOFA; g-qSOFA: Geriatric-quickSOFA; ICU: Intensive Care Unit; SPMSQ: Short Portable Mental Status Questionnaire; CCl: Charlson Comorbidity Index; SBP: Systolic Blood Pressure; RR: Respiratory Rate; OR: Odds Ratio; Cl: Confidence Interval; BADL: Basic Activities Of Daily Living; IADL: Instrumental Activities of Daily Living; DSM-5th: Diagnostic and Statistical Manual of Mental Disorders 5th Edition criteria

\section{Acknowledgements}

The authors thank the patients, their families and all investigators who participated in the study.

\section{Authors' contributions}

Conceptualization - F.R., F.C., A.V., I.M., A.Z., S.S., S.V.; writing - original draft preparation - F.R.; writing - review and editing - A.Z., S.S., S.V.; tables - F.R., F.C. with edits from S.V.; visualization/figure - F.R., S.V.. The author(s) read and approved the final manuscript.

\section{Funding}

This research did not receive any funding.
Availability of data and materials

The datasets of the current study are available from the corresponding author on reasonable request.

\section{Declarations}

Ethics approval and consent to participate

The study protocol received ethical approval by the Ethics Committee of the University of Ferrara. Written consent is obtained from all participants. The data used in this study were anonymized before its use.

We confirm that all methods were carried out in accordance with relevant guidelines and regulations.

\section{Consent for publication}

Not applicable.

\section{Competing interests}

The authors have not conflict of interest.

\section{Author details}

'Department of Medical Sciences, University of Ferrara, Ferrara, Italy. ${ }^{2}$ Geriatrics Unit, Azienda Ospedaliero- universitaria di Ferrara, Ferrara, Italy. ${ }^{3}$ Anestesiology and Resuscitation Unit, Department of Morfology, Surgery and Sperimental Medicine, University of Ferrara, Ferrara, Italy. ${ }^{4}$ Orthogeriatrics Unit, Azienda Ospedaliero-Universitaria di Ferrara, Via Aldo Moro, 8, 44124 Ferrara, Italy.

Received: 8 February 2021 Accepted: 26 March 2021

Published online: 13 April 2021

\section{References}

1. Singer M, Deutschman CS, Seymour CW, et al. The sepsis definitions task force the third international consensus definitions for sepsis and septic shock (sepsis-3). JAMA. 2016;315:762-74.

2. Mankowski RT, Anton SD, Ghita GL, et al. Older sepsis servivors suffer persistent disability burden and poor ling-term survival. J Am Geriatr Soc. 2020;68:9.

3. Riegel B, Huang L, Mikkelsen ME, et al. Early post-intensive care syndrome among older adult sepsis survivors receiving home care. J Am Geriatr Soc. 2018;67:3.

4. Canora J, Moreno G, Marco J, et al. Admittances characteristics by sepsis in the Spanish internal medicine services between 2005 and 2015: mortality pattern. Postgrad Med. 2020;132(3):296-300. https://doi.org/10.1080/003254 81.2020.1718388.

5. Fedeli U, Piccinni P, Schievano E, Saugo M, Pellizzer G. Growing burden of sepsis-related mortality in northeastern Italy: a multiple causes of death analysis. BMC Infect Dis. 2016;16(1):330. https://doi.org/10.1186/s12879-016-1 664-2.

6. Levy MM, Evans LE, Rhodes A. The surviving sepsis campaign bundle: 2018 update. Crit Care Med. 2018;46(6):997-1000. https://doi.org/10.1097/CCM. 0000000000003119

7. Sonneville R, Verdonk F, Rauturier C, Klein IF, Wolff M, Annane D, et al. Understanding brain dysfunction in sepsis. Ann Intensive Care. 2013;3(1):15. https://doi.org/10.1186/2110-5820-3-15.

8. Yoshikawa TT, Reyes BJ, Ouslander JG. Sepsis in older adults in long-term care facilities: challenges in diagnosis and management. J Am Geriatr Soc. 2019;67:11.

9. Singer BH, Dickson RP, Denstaedt SJ, Newstead MW, Kim K, Falkowski NR, et al. Bacterial dissemination to the brain in sepsis. Am J Respir Crit Care Med. 2018;197(6):747-56. https://doi.org/10.1164/rccm.201708-15590C.

10. Zaccone V, Tosoni A, Passaro G, Vallone CV, Impagnatiello M, Li Puma DD, et al. Sepsis in internal medicine wards: current knowledge, uncertainties and new approaches for management optimization. Ann Med. 2017;49(7): 582-92. https://doi.org/10.1080/07853890.2017.1332776.

11. Vincent JL, Moreno R, Takala J, et al. The SOFA (Sepsis-related organ failure assessment) score to describe organ dysfunction/failure. On behalf of the working group on sepsis-related problems of the European Society of Intensive Care Medicine. Intensive Care Med. 1996;22(7):707-10. https://doi. org/10.1007/BF01709751. 
12. Ferreira FL, Bota DP, Bross $A$, Mélot $C$, Vincent JL. Serial evaluation of the SOFA score to predict outcome in critically ill patients. JAMA. 2001;286(14): 1754-8. https://doi.org/10.1001/jama.286.14.1754.

13. Geyik D, Yücel Y, Erkal K, et al. The use of quick sofa (Qsofa) in elderly patients with sepsis in the intensive care unit. Turk J Geriatr. 2018;21:143-39.

14. Remelli F, Fogagnolo A, Zurlo A, et al. Prognostic factors in older patients admitted in ICU with diagnosis of abdominal sepsis (sepsis-3 criteria). J Gerontol Geriatr. 2020;68:1-7.

15. Haas LEM, Termorshuizen F, de Lange DW, et al. Performance of the quick SOFA in very old ICU patients admitted with sepsis. Acta Anaesthesiol Scand. 2020;64(4):508-16. https://doi.org/10.1111/aas.13536.

16. Chang SH, Yeh CC, Chen YA, et al. Quick-SOFA score to predict mortality among geriatric patients with influenza in the emergency department. Medicine. 2019;98:15966.

17. Bastoni D, Ticinesi A, Lauretani F, Calamai S, Catalano M, Catania P, et al. Application of the sepsis-3 consensus criteria in a geriatric acute care unit: a prospective study. J Clin Med. 2019;8(3):359. https//doi.org/10.3390/jcm8030359.

18. Papadimitriou-Olivgeris M, Psychogiou R, Garessus J, Camaret AD, Fourre N, Kanagaratnam $\mathrm{S}$, et al. Predictors of mortality of bloodstream infections among internal medicine patients in a Swiss hospital: role of quick sequential organ failure assessment. Eur J Intern Med. 2019;65:86-92. https://doi.org/10.1016/j.ejim.2019.05.003.

19. Mirijello A, Tosoni A, Zaccone V, Impagnatiello M, Passaro G, Vallone CV, et al. MEDS score and vitamin D status are independent predictors of mortality in a cohort of internal medicine patients with microbiological identified sepsis. Eur Rev Med Pharmacol Sci. 2019;23(9):4033-43. https://doi. org/10.26355/eurrev_201905_17834.

20. American Psychiatric Association DSM-5 Task Force. Diagnostic and statistical manual of mental disorders 5th edi-tion, DSM-5: American Psychiatric Association; 2013. https://doi.org/10.1176/appi.books.9780890425596.

21. Deyo RA, Cherkin DC, Ciol MA. Adapting a clinical comorbidity index for use with ICD-9-CM administrative databases. J Clin Epidemiol. 1992;45(6):613-9. https://doi.org/10.1016/0895-4356(92)90133-8.

22. Inouye SK, Charpentier PA. Precipitating factors for delirium in hospitalized elderly persons. JAMA. 1996;275(11):852-7. https://doi.org/10.1001/jama.1 996.03530350034031.

23. Pitkala KH, Laurila JV, Strandberg TE, Tilvis RS. Prognostic significance of delirium in frail older people. Dement Geriatr Cogn Disord. 2005;19(2-3): 158-63. https://doi.org/10.1159/000082888.

24. Siddiqi N, House AO, Holmes JD. Occurrence and outcome of delirium in medical in-patients: a systematic literature review. Age Ageing. 2006;35(4): 350-64. https://doi.org/10.1093/ageing/afl005.

25. Han JH, Shintani A, Eden S, Morandi A, Solberg LM, Schnelle J, et al. Delirium in the emergency department: an independent predictor of death within 6 months. Ann Emerg Med. 2010;56(3):244-52. https://doi.org/10.101 6/j.annemergmed.2010.03.003.

26. Martin GS, Mannino DM, Moss M. The effect of age on the development and outcome of adult sepsis. Crit Care Med. 2006;34(1):15-21. https://doi. org/10.1097/01.CCM.0000194535.82812.BA.

27. Khurana V, Gambhir IS, Kishore D. Evaluation of delirium in elderly: a hospital-based study. Geriatr Gerontol Int. 2011;11(4):467-73. https://doi. org/10.1111/j.1447-0594.2011.00710.x.

28. Teasdale $G$, Jennet B. Assessment of coma and impaired consciousness. A practical scale. Lancet. 1974;2(7872):81-4. https://doi.org/10.1016/s0140-673 6(74)91639-0.

29. Anderson TS, Marcantonio ER, McCarthy EP, et al. National trends in potentially preventable hospitalizations of older adults with dementia. J Am Geriatr Soc. 2020;68:10

\section{Publisher's Note}

Springer Nature remains neutral with regard to jurisdictional claims in published maps and institutional affiliations.

Ready to submit your research? Choose BMC and benefit from:

- fast, convenient online submission

- thorough peer review by experienced researchers in your field

- rapid publication on acceptance

- support for research data, including large and complex data types

- gold Open Access which fosters wider collaboration and increased citations

- maximum visibility for your research: over $100 \mathrm{M}$ website views per year

At BMC, research is always in progress.

Learn more biomedcentral.com/submissions 